ECCOMAS

Proceedia
COMPDYN 2021

$8^{\text {th }}$ ECCOMAS Thematic Conference on Computational Methods in Structural Dynamics and Earthquake Engineering M. Papadrakakis, M. Fragiadakis (eds.) Streamed from Athens, Greece, 28 - 30 June 2021

\title{
SEISMIC ASSESSMENT OF AN EXISTING RC BUILDING AFFECTED BY SLOW-MOVING LANDSLIDES INDUCED DISPLACEMENTS MONITORED BY REMOTE SENSING TECHNIQUE
}

\author{
Annalisa Mele ${ }^{1}$, Andrea Miano ${ }^{1}$, Diego di Martire ${ }^{2,3}$, Donato Infante ${ }^{3}$, Andrea Prota ${ }^{1}$ \\ and Massimo Ramondini ${ }^{3,4}$ \\ ${ }^{1}$ Department of Structures for Engineering and Architecture, University of Naples Federico II \\ 80125, Naples, Italy \\ \{annalisa.mele; andrea.miano; aprota@unina.it\} \\ ${ }^{2}$ Department of Earth, Environment and Resources Sciences, University of Naples Federico II \\ 80126, Naples, Italy \\ diego.dimartire@unina.it \\ ${ }^{3}$ SINTEMA Engineering srl, Spin-Off University of Naples Federico II \\ 80134, Naples, Italy \\ sintemasrl@gmail.com \\ ${ }^{4}$ Department of Civil, Architectural and Environmental Engineering, University of Naples Federico II \\ 80125, Naples, Italy \\ ramondin@unina.it
}

\begin{abstract}
The seismic assessment of reinforced concrete $(R C)$ structures is commonly carried out neglecting previous damage, eventually induced by other phenomena, although different forms of hazard can affect a structure during its existence. The coexistence of many hazard sources is very common, i.e., in countries affected by landslides, also characterized by high seismicity, like Italy. The aim of this work is both to demonstrate the potential utility of satellite data derived from the Differential Synthetic Aperture Radar Interferometry (DInSAR) to support the structural health monitoring of a $R C$ infilled building within a landslide-affected area and to assess its safety conditions after experiencing two different hazards, that are landslide and earthquake. A $3 D$ model of the case study building, including also infills, is created based on the information available from a geometrical survey, obtaining the missing parameters from literature. The seismic assessment of the building structural elements, caused by the design seismic action, is initially shown. Then, the seismic assessment is repeated, considering the building to be in a state of known landslide-induced stress-strain condition. Finally, an interesting comparison is proposed between the safety condition of the building expected in both cases, with or without the consideration of the precedent landslide-induced displacements.
\end{abstract}

Keywords: Multi-Hazard Assessment, Existing RC Buildings, Remote sensing, Earthquake, Landslide, Damage Assessment 
Annalisa Mele, Andrea Miano, Diego di Martire, Donato Infante, Andrea Prota and Massimo Ramondini

\section{INTRODUCTION}

Different forms of hazard can affect structures throughout their existence; this is very common, for example, in countries affected both by landslides and high seismicity.

The effects of the single hazard source on existing reinforced concrete (RC) buildings have been a widely discussed research topic worldwide, in the last decades. For the seismic assessment, the international literature includes many methodologies and applications related to specific investigation issues [1-4]. Many studies can also be found regarding the evaluation of the structural damage as consequence of phenomena inducing slow displacements, monitored through satellite data for consistent periods [5-7], in particular for landslides [8-12]. The research in terms of landslide-earthquake multi-risk analysis, indeed, is very limited [13].

In this work, a RC infilled building, constructed in the 60s, located in Moio della Civitella, South of Italy, having typical structural deficiencies of pre-seismic designed structures, is used as case study. A structural 3D model of the building, including infills, is created based on the information available from original documents and an in-situ survey, while the missing parameters are obtained from literature. A modeling approach specifically elaborated for RC members with plain bars [14] is implemented for the non-linear flexural behavior of RC members, concentrating it at the ends of the beams and columns. Couples of diagonal struts are used for infills modeling, which behavior is defined as illustrated by Panagiotakos and Fardis [15].

The effect of the landslide phenomenon on the structure is monitored through the Differential Synthetic Aperture Radar Interferometry (DInSAR) technique [16]. The processing of ascending and descending COSMO-SkyMed images allows to obtain DInSAR deformation data, as a result of detected displacements of targets on the ground (buildings, rocks, infrastructures, etc.), with accuracy of the millimeter, carrying out maps of mean displacement rates and time series of deformations [17-19]. The surface ground movements, detected in the period 20122019 , and extended to the 2020, have been applied to building foundations.

Then, non-linear static (pushover) analysis procedure is implemented twice: the first time in a condition of integer structure (earthquake [EQ] scenario) and the second time considering the structure already affected by the monitored slow-moving landslide (landslide plus earthquake [LAN+EQ] scenario). In both situations, the analysis results allow to carry out codebased $[20,21]$ seismic safety assessments, and the calculation of the "seismic safety index" (called for brevity "safety index") [22, 23] with reference to the Italian Life-Safety (LS) limit state (ls) [20].

This paper aims to demonstrate the potential utility of DInSAR technique at a small scale, to support the structural health monitoring of an $\mathrm{RC}$ building, and to demonstrate the importance of a multi-risk seismic safety assessment, cumulating the actions coming from the two different hazards, that are landslide and earthquake.

\section{METHODOLOGY}

The fundamental input for the multi-risk analysis, in this work, is the landslide advanced monitoring, for a quite wide period of time, obtained from the DInSAR technique. Then, the aims of the work is pursued by performing pushover analysis and, therefore, the seismic safety local checks for RC members and the global safety index assessment for the whole structure. The theorical basis of the previous approaches are explained, respectively, in Section 2.1 and Section 2.2. The territorial frame of the case study, its information and the modeling aspects are reported in Section 3. Moreover, Section 4.1 and Section 4.2 present the DInSAR analysis and displacements application, and the seismic structural assessment for the case 
study building, in the EQ and LAN+EQ scenario. In conclusion, the results obtained by the multi-risk analysis are compared with the results of the traditional one.

\subsection{Differential SAR Interferometry technique}

DInSAR approach is based on time series of radar images [24] acquired by sensors installed on satellite platforms, travelling along semi-polar orbits. The acquisition is ensured when the observation of radar targets, namely Permanent Scatterers (PS) [25], is possible. PSs are typically parts of buildings, metallic structures, rocks or other elements already present on the ground, with electromagnetic characteristics more or less constant over time. Having a stack of images on the same area, in which specific PSs can be identified, DInSAR approach allows to create maps of mean displacement rates and time series of the deformations measured along the LoS, with an accuracy of the millimeter. The mentioned type of maps can also be obtained for more significative directions with respect to the phenomena developing on Earth surface. This is possible considering that, because of the Earth rotational movement, an area can be enlightened by a Synthetic Aperture Radar (SAR) sensor, either from East or from West, along descending (from North to South) or ascending orbits (from South to North), respectively. Descending and Ascending acquisitions can be combined, after the definition of a $\mathrm{x}, \mathrm{y}, \mathrm{z}$ Cartesian coordinate system, in which the three directions coincide with the horizontal $\mathrm{E}-\mathrm{W}$ and N-S and vertical, respectively, thus obtaining the displacement vector. It is important to underline that, due to the geometrical characteristics of the acquisition system the $\mathrm{N}-\mathrm{S}$ direction is considered negligible [17]. This is a DInSAR technique limit, that, consequently, furnishes deformation components only in the horizontal E-W and vertical directions.

\subsection{Seismic assessment framework}

The pushover analysis is implemented, through a step-by-step procedure, by subjecting the structure to two monotonically increasing pattern of lateral forces, as recommended in NTC (2018) [20]. The lateral forces, one proportional to the fundamental mode of vibration (Mode $\mathrm{X}$ and Mode $\mathrm{Y}$ ), one proportional to the mass distribution (Mass X and Mass Y), are applied in the model at the centers of floor mass ( $\mathrm{X}$ and $\mathrm{Y}$ directions are assumed accordingly to Fig. $2(a))$. Then, the so-called "inelastic demand point", $D_{\text {inel }}$ is determined, through method A of the standard [26], based on [27], in the Acceleration Displacement Response Spectrum space (ADRS, $[28,29]$ ).

Once the results of the pushover analysis are obtained, the seismic safety checks are reported in this work for the LS-ls [20], equivalent to the Limit State of Significant Damage (SD) defined in EC8-3 [21]. The structural checks in the inelastic demand point $D_{\text {inel }}$ at LS-ls are performed with regards to ductile and brittle mechanisms. The structural capacity of beams and columns in ductile terms, $\theta_{u}$, is evaluated according to the capacity model suggested by [26] and [21], in terms of chord rotation capacity. The brittle failures for beams, columns and beam-column joints are checked according to capacity models suggested by the codes $[21,26,30]$.

The seismic structural assessment allows the determination of the inelastic "performance point" of the structure, $C_{\text {inel }}$, at the considered $l s$, as that point in which the very first structural element experiences a failure mechanism. From $C_{\text {inel }}$ it is possible to individuate its elastic correspondent point, $C_{e l}$, necessary to find the "capacity spectrum" of the structure, in the ADRS space. The latter, defined as the elastic spectrum that pushes the structure in crisis, is a fundamental element to quantify the structural safety condition. In fact, the safety index, $\zeta_{E}$ $[22,23]$, is defined as the ratio between the demand PGA, based on the design seismic action prescribed by the code for the LS- $l s$, and the capacity PGA of the building, represented by the 
anchor acceleration of the capacity spectrum. The structure can be considered safety against seismic actions when $\zeta_{E}$ assumes values greater than one.

\section{CASE STUDY AND MODEL DESCRIPTION}

\subsection{Case study description}

The case study RC building is located in the town of Moio della Civitella (Campania Region, Southern Italy), composed of two urban centres, Moio and Pellare. According to the Hydro-geomorphological Setting Plan of Hydrographic District of the Southern Apennines (HDSA)[32], building is affected by significant foundation displacements as a consequence of an intermittent landslide phenomenon with slow kinematics, (Fig. 1), as also presented in [33-35].

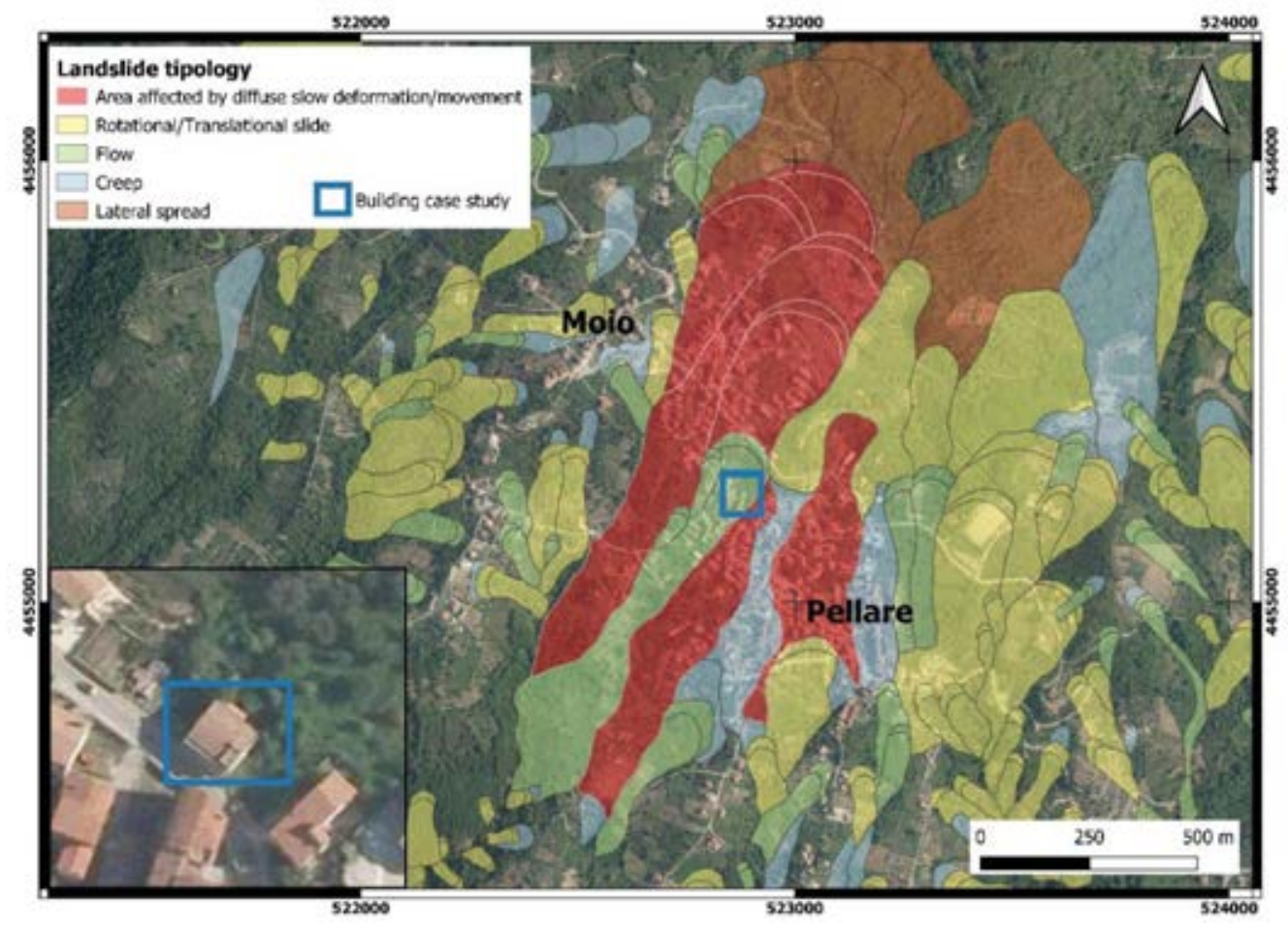

Fig. 1. Landslide inventory map (2012) with location of considered building.

The RC building was constructed in 1960s, and designed for gravitational loads only, with a plane parallel frames structural system; it is independent, with a rectangular plan of $11,90 \mathrm{~m}$ by $11,95 \mathrm{~m}$, terraces excluded, built on three levels, with a pitched roof (Fig. 2(a-c)).

The most recent of many visual surveys conducted in the last decade, refers to December 2020. From the in situ-inspections, it has been possible to determine the following information. Columns have rectangular cross sections of dimensions $40 \times 55 \mathrm{~cm}$ or $40 \times 40 \mathrm{~cm}$, except the stair columns, that are $55 \times 50 \mathrm{~cm}, 60 \times 35 \mathrm{~cm}$ and $55 \times 40 \mathrm{~cm}$. They are reinforced with smooth bars, 4 longitudinal ones, $\phi 16$, and stirrups $\phi 6 / 20 "$ Fig. $2(d)$. The primary beams, belonging to plane frames, and the secondary beams, that orthogonally link the four frames at the ends, have $35 \times 60 \mathrm{~cm}$ and $20 \times 50 \mathrm{~cm}$ rectangular cross sections, respectively.

The missing information about the beams reinforcement have been obtained by a simulated design, following the Italian standard R.D.L. [36], according to which the structure has been designed, then combining its results with evidence of local engineers about the construction procedures of the building period. Therefore, longitudinal bars $\phi 16$ have been adopted: $9+3$ 
for the primary beams, while $3+2$ for the secondary beams. Moreover, a transversal reinforcement of $\phi 6 / 15$ " has been utilized.

Regarding the mechanical materials properties, literature references have been employed. For the reinforcement bars, it is assumed the presence of Aq.42 steel, with an average yield strength $f_{y m}$ of 328,6 Mpa, from the work of Verderame et al. [37], and an elastic modulus $E$ of $200000 \mathrm{MPa}$. For the concrete, a cylindric mean compressive strength $f_{c m}$, of $21,3 \mathrm{MPa}$, according to Verderame et al. [38], and an elastic modulus, E, of $27607 \mathrm{MPa}$ have been used.

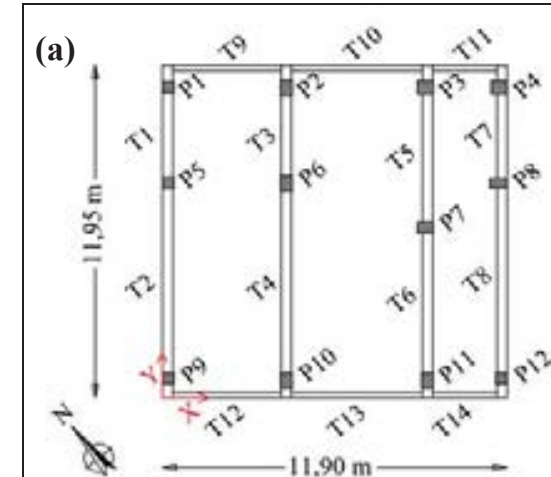

(b)

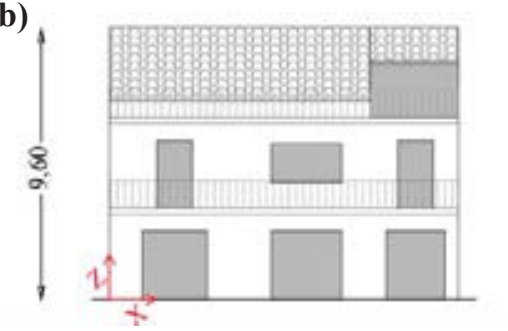

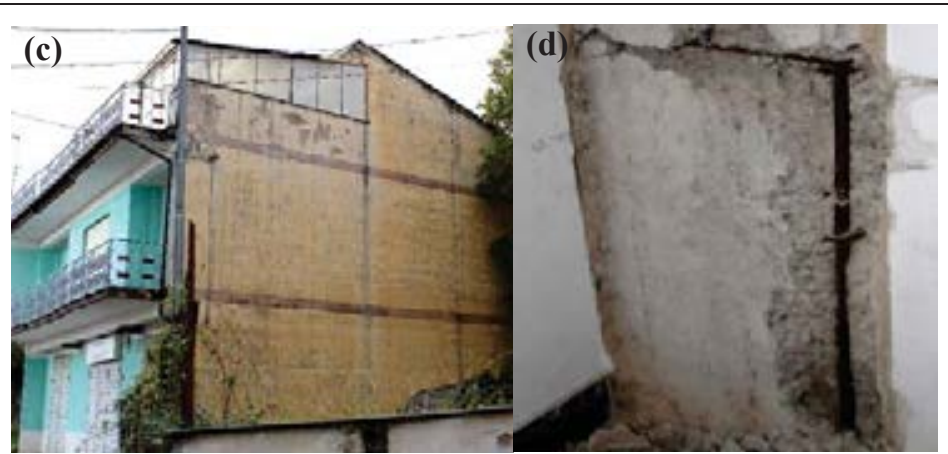

(e)

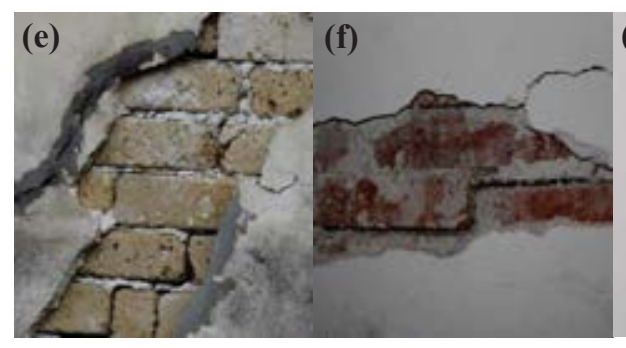

(g)

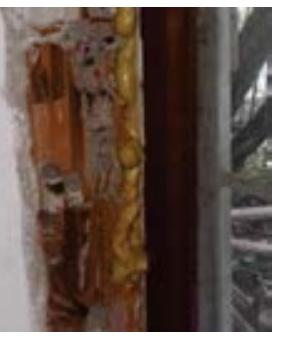

Fig. 2. Schematic geometrical plan (a) and front view of the S-W façade (b). In situ survey (December 2020): external picture (c); vertical smooth bars found at the column base (d); infills details - tuff (e); solid clay bricks (f); hollow clay bricks (g).

Different types of infills have been found during the in-situ inspection, as shown in Fig. 2 $(e-g)$ : double-leaf vertical hollow clay bricks with a thickness of $8+12 \mathrm{~cm}$, then $12+12 \mathrm{~cm}$ solid clay bricks and finally regular tuff with a thickness of $25 \mathrm{~cm}$. A clear schematization of the different infills types distribution, with a labelling of the building fields, can be found in Fig. 3. In particular, hollow clay bricks, solid clay bricks and tuff are indicated with blue, orange and green lines, respectively. Moreover, it can be noted that $\mathrm{AB}, \mathrm{BC}, \mathrm{A}^{\prime} \mathrm{B}$ ' and $\mathrm{B}^{\prime} \mathrm{C}^{\prime}$ are the fields including only infills without openings (solid lines), while CD, DE, EF, C'D', D'E' and E'F' are the fields including also infills with openings (dashed lines). 
(a)

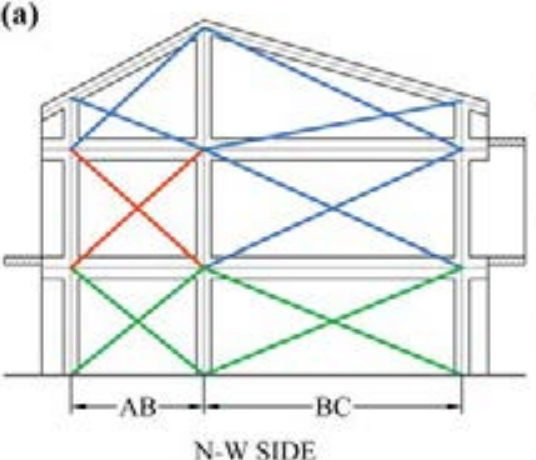

(c)

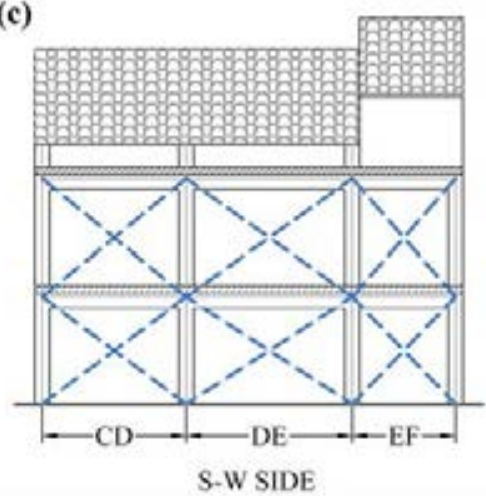

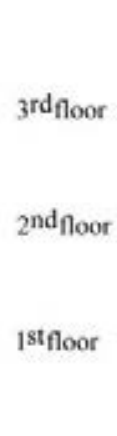

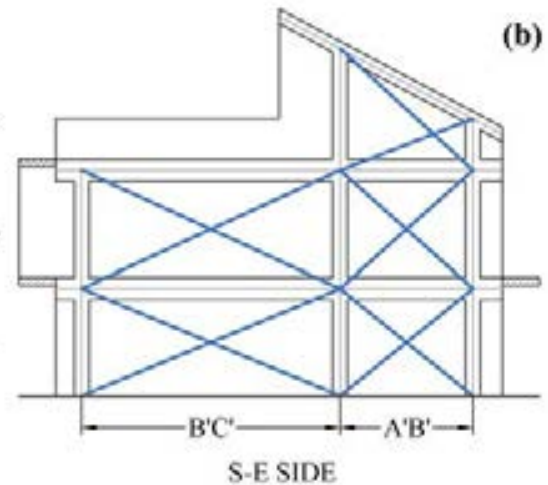

S-E SIDE

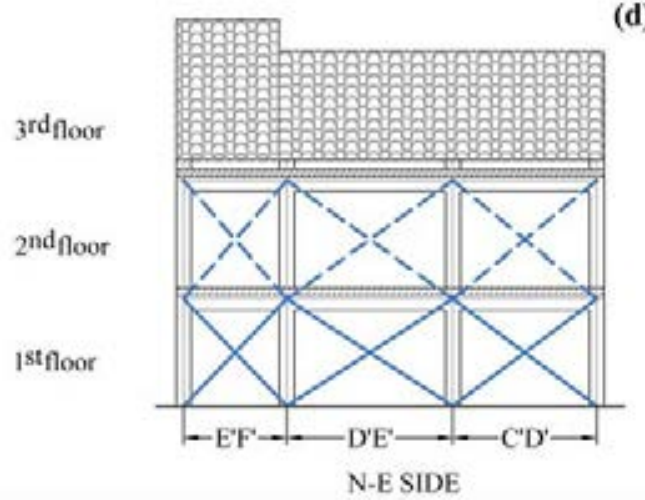

Fig. 3. Building prospects with identification of the different infills types of the building (hollow clay bricks, blue lines; solid clay bricks, orange lines; tuff bricks, green lines) differentiated in: without openings (continuous lines, (a-b)) and with openings (dashed line, (c- d)).

Mechanical properties for tuff and solid clay bricks have been derived from Italian NTC (2018) [20]; for hollow clay bricks, they have been assumed from [39] (see Tab. 1).

\begin{tabular}{cccc} 
Mechanical Property & Tuff & Hollow clay bricks & Solid clay bricks \\
\hline Elastic modulus $\mathrm{E}_{\mathrm{mh}}\left[\mathrm{N} / \mathrm{mm}^{2}\right]$ & 1410 & 1255 & 1500 \\
Shear modulus $\mathrm{G}_{\mathrm{mh}}\left[\mathrm{N} / \mathrm{mm}^{2}\right]$ & 450 & 315 & 500 \\
Tensile strength $\tau_{0}\left[\mathrm{~N} / \mathrm{mm}^{2}\right]$ & 0,060 & 0,215 & 0,09 \\
\hline
\end{tabular}

Tab. 1. Mean values of infills mechanical properties.

\subsection{Modeling description}

As regards the non-linear flexural behavior of RC members, a fourth-linear moment-chord rotation modeling approach, specifically elaborated for plain bars [14], has been adopted. The non-linear flexural behavior has been assigned as a plastic hinge at each end cross section of beams and columns. It has been verified that bending failures precede the shear for the $\mathrm{RC}$ members. However, these elements have been verified with respect to shear mechanisms in post processing, using code formulations as suggested in Section 2.2. Moreover, each infill has been modeled with a couple of equivalent diagonal struts resistant to compression, according to Al-Chaar [40] and Fardis [41], with a lateral response modeled following the equivalent single strut model proposed by Panagiotakos and Fardis [15]. The three-linear moment-chord rotation bond has been assigned at the middle cross section of each diagonal strut as axial hinges. More details about the evaluation of the geometric characteristics of these infills can be found in [12]. 
Based on the acquired geometrical and mechanical information, a 3D FEM structural model has been created using SAP2000 (v. 21.0.2, [42]). 2-D elements have been used for modeling beams, columns and the couple of diagonal struts representing the infills. The base columns have been fixed to consider the presence of foundations. The last floor has been modeled such that its height creates an equivalence of areas of the infills between the second and third order beams. The infills of the third floor, with openings, have been considered only as line masses and as line loads, because of the significant difference in shape from the panels used in the model proposed by Panagiotakos and Fardis [15]. The ones in the fields AB, BC and $\mathrm{A}^{\prime} \mathrm{B}^{\prime}$ have been modelled; finally, there is a parapet in the $\mathrm{B}^{\prime} \mathrm{C}^{\prime}$ field, and in the EF field there is no infill because of the presence of a veranda.

The elastic vibration periods of the 3D model, for the first two vibration modes, are $\mathrm{T}_{1}=0,47 \mathrm{~s}$ and $\mathrm{T}_{2}=0,39 \mathrm{~s}$, in the direction with and without openings, respectively.

\section{SEISMIC ASSESSMENT WITHOUT AND WITH CONSIDERATION OF THE PRECEDENT LANDSLIDE-INDUCED DISPLACEMENTS}

\subsection{DInSAR analysis and displacements application for the case study building}

Cosmo-SkyMed images, obtained in the framework of MapItaly Project [43], were processed by means of DInSAR technique. In detail, X-band stripmap in ascending and descending mode images, characterized by a ground resolution of $3 \times 3 \mathrm{~m}$, were processed using SUBSIDENCE software. Coherent Pixel Technique-Temporal Phase Coherence (CPT-TPC) approach $[44,45]$ has been used to obtain ground displacements from satellite radar images. A detailed description of the whole algorithm can be consulted in [44, 45]. A phase quality value equal to 0,7 has been set in order to obtain an acceptable displacement error, lower than $1,5 \mathrm{~mm}$, and to select an adequate number of points. Fig. $4(a, b)$ shows mean displacement rates maps for ascending and descending acquisitions.

Starting from the discrete maps, vertical and horizontal E-W displacement components, with millimeter accuracy, have been obtained at the end of each year in the period 2012-2018 and for the first three months of 2019 , by a combination process. In this way, the profiles of cumulated vertical and horizontal (in the direction parallel to the building sides) displacements, occurred to building foundations, have been provided. Moreover, to obtain the cumulated displacement components at the end of 2019 and 2020, an extrapolation has been done, based on the hypothesis that the landslide phenomenon keeps evolving linearly in time, as observed in the monitored period. The cumulate displacement profiles are shown in Fig. $4(c, d)$. The monitoring of the landslide that caused ever-increasing displacements of the foundation soil over the years can be also considered as base to carefully hypothesize the condition of the future years in order to program typical retrofit operation on the RC building [46] or to make prediction loss assessment evaluation for structures/infrastructures portfolio [47]. 


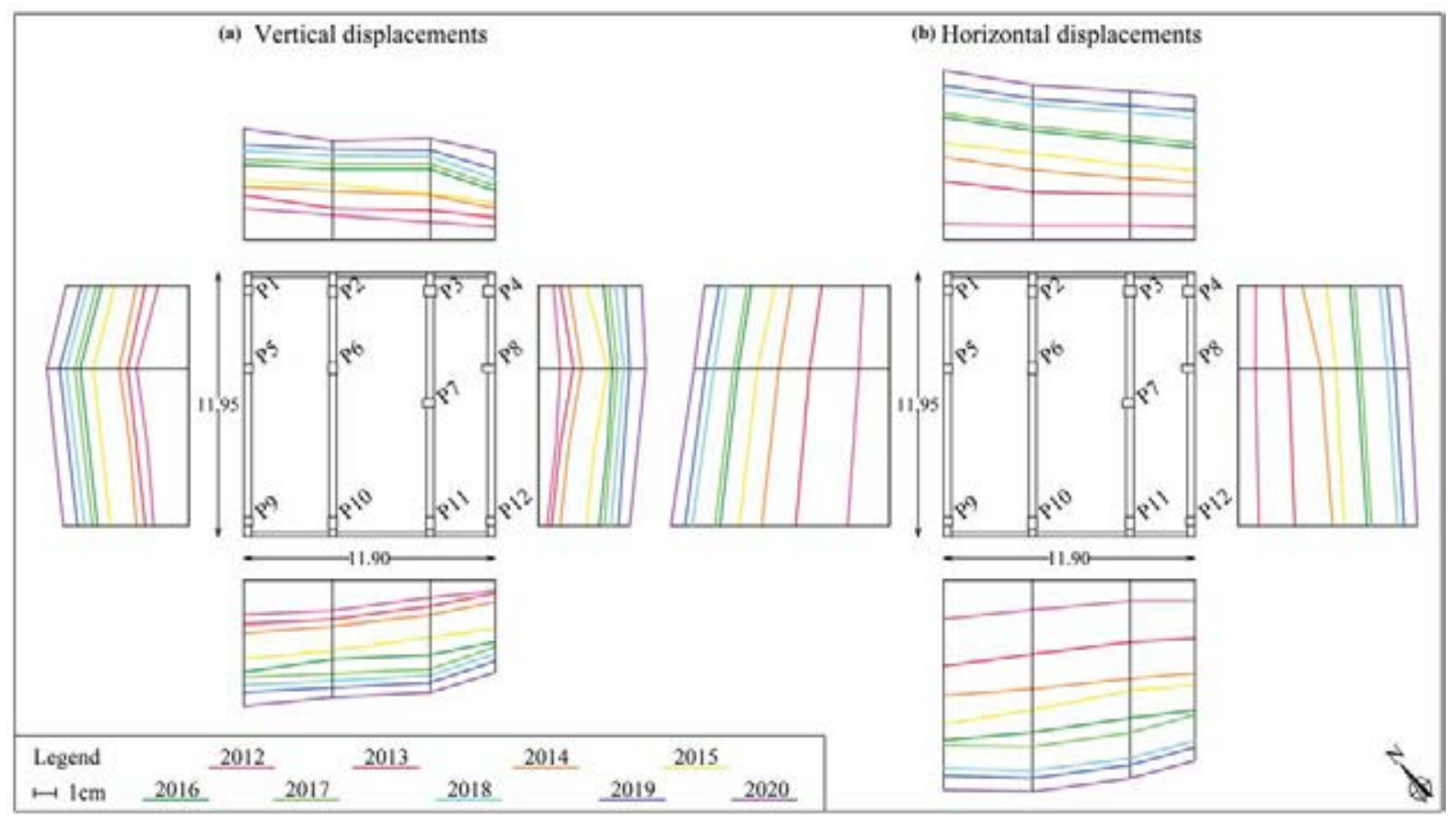

Fig. 4. Foundation displacement profiles the end of each year in the period 2012-2020: vertical (a) and horizontal (b).

\subsection{EQ and LAN+EQ results and comparisons}

As mentioned in Section 2.2 as first step of the proposed methodology, the seismic capacity of the RC elements at the LS- $l s$ has been evaluated, after the definition of the seismic action according to Italian NTC (2018) [20].

The first case investigated is the EQ scenario, in which the building is in a deformed condition only for gravity loads before the application of the seismic action. Then, in the LAN+EQ scenario, the seismic assessment procedure is implemented on the structure, already deformed because of the differential slow-moving landslide-induced displacements, applied at the base of the first-floor columns.

Following what illustrated in Section 2.2, pushover analysis has been implemented, by applying two monotonically increasing pattern of lateral forces to the structure, as recommended in NTC (2018) [20]. The resultant pushover curves are represented in Fig. 5. It can be observed that LAN+EQ scenario's curves (black dotted lines) start from a significant displacement value of the control point induced by the landslide effect, while EQ scenario's curves (grey continuous lines) start from quite null values of roof displacement.

The seismic verifications in terms of ductile and fragile mechanisms in the step corresponding to the inelastic demand point $D_{\text {inel }}$, for the LS- $l s$, have been carried out once obtained the results of the pushover analysis. In Fig. 5, also the evolutions of the failure sequences found for both scenarios are compared. In both cases, the first failure mechanism attained is the tensile-shear failure in beam-columns unconfined joints (represented with red triangles), followed by brittle shear failures in the beams (orange squares) and in the columns (yellow circles). For each load case, ductile failures are never achieved at LS- $l s$, up to $D_{\text {inel }}$ (indicated with a green pentagram).

The application of the differential landslide-induces displacements provokes an aggravation of the stress state in the structural elements. In fact, they enter in crisis for lower steps with respect to those attained in the EQ scenario; moreover, the number of elements in crisis at the LS- $l s$, until the corresponding $D_{\text {inel, }}$ increases. In particular, in the LAN+EQ scenario, 
the first joint failures happen at the step zero of the pushover, meaning that they are caused by the action of the landslide, before the application of the seismic action.

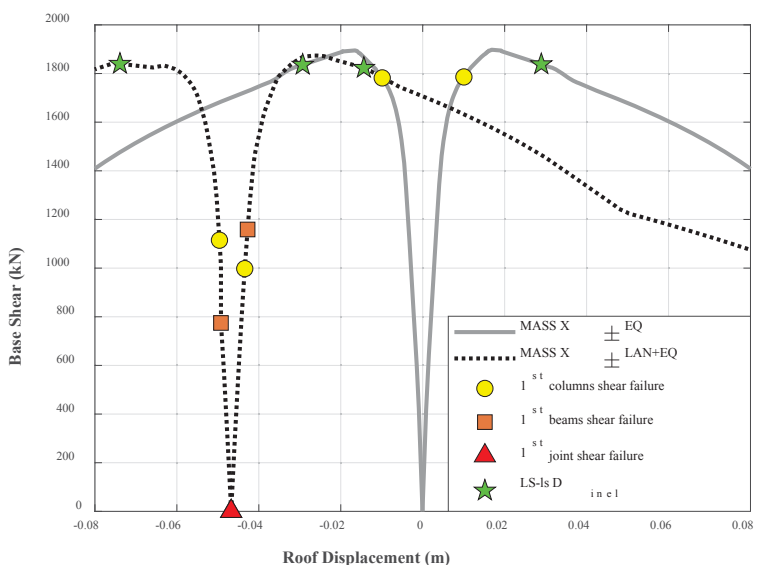

(a)

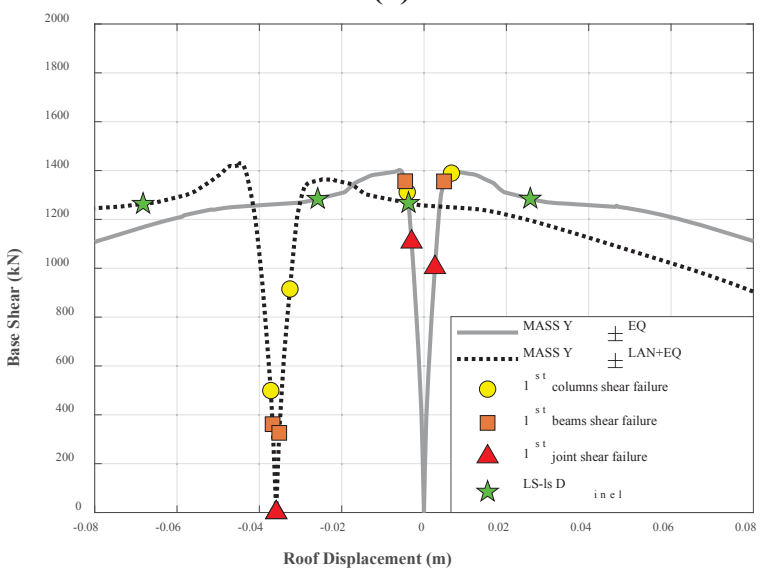

(c)

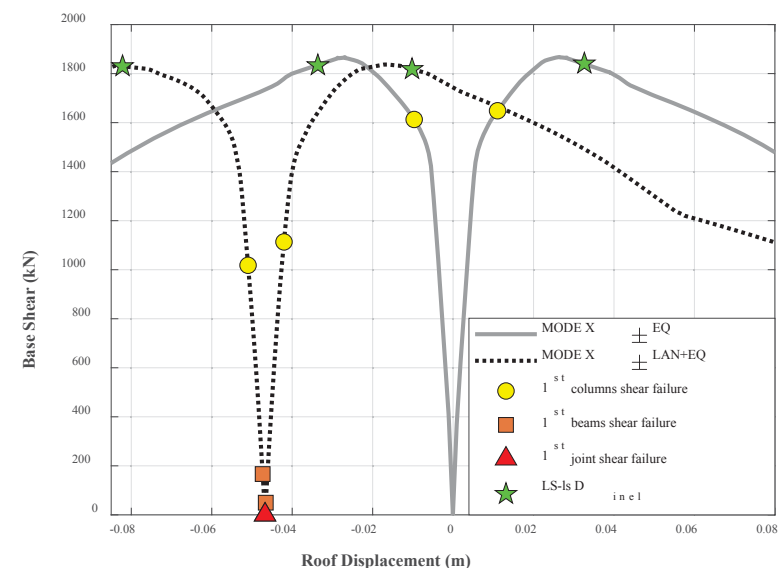

(b)

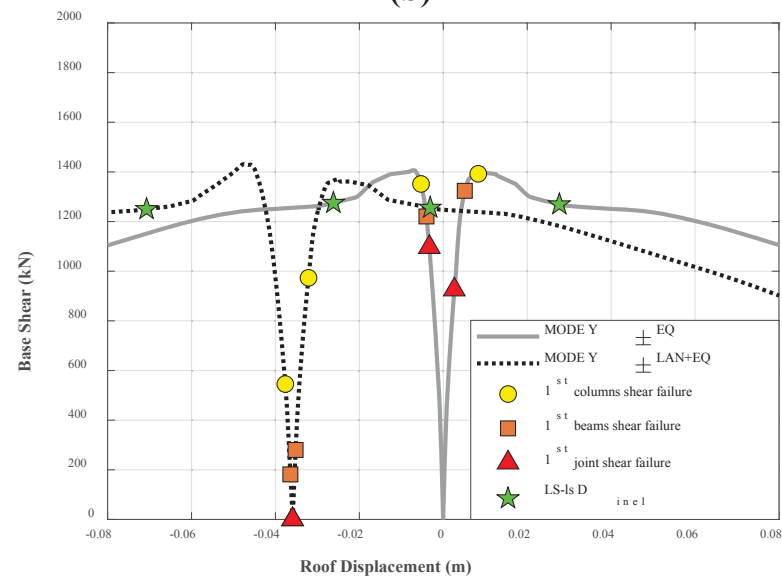

(d)

Fig. 5. Comparison of the pushover curves and relative failure mechanism progress of structural elements, until the demand point, in the EQ and LAN+EQ scenarios: Mass X (a), Mode X (b), Mass Y (c) and Mode Y (d).

It can be observed that, from EQ scenario to LAN+EQ scenario, the number of elements experiencing brittle crises at LS-ls passes from 11 to 19 for joints, from 7 to 17 for columns and from 2 to 8 for beams. This increase of the number of elements exceeding the $l s$ can be attributed to the action of the landslide, which is active independently from the earthquake.

Moreover, an overall comparison of the global structural condition between the two scenarios has been done in terms of safety index, $\zeta_{E}$ as suggested in Section 2.2. In the EQ scenario, the safety index at LS- $l s$ is equal to 0,27 . Taking into account the previous landslide phenomenon with the first failure at the step zero of the curves, according to Sisma-Bonus Guidelines [48], the spectrum referred to the Beginning of Damage- $l s$ (10 years return period) has been considered as a lower limit for the determination of PGA capacity. The result is that in LAN+EQ scenario, a $\zeta_{E}$ of 0,11 has been obtained. In both cases the structure shows a lack of seismic capacity, meaning that it is able to withstand only a little percentage of the total design seismic action.

\section{CONCLUSIONS}

This study presented the seismic safety assessments of an existing RC infilled building, constructed in the $60 \mathrm{~s}$, located in a landslide-affected area. The work has a dual purpose. 
From one side, it shows how the DInSAR satellite data can be used to support the structural health monitoring of RC buildings affected by slow-moving landslides. In general, the presented methodology can be applied also to phenomena with a different origin, if slowly evolving in time. On the other side, the aim is to highlight the importance of the seismic safety assessment in a multi-risk analysis, cumulating the action coming from the two different hazards, that in the specific case are the landslide and the seismic action.

The DinSAR remote sensing technique has been used for the detection of the landslideinduced displacements, confirming to be an extremely effective tool not only for the monitoring of phenomena at a territorial scale, but also with refers to the detail scale. A structural 3D model of the building, considering infills, has been implemented, to carry out the seismic assessment in two phases. Initially, a traditional seismic assessment, based on non-linear static analysis, has been done. Then, the landslide-induced displacements obtained by DInSAR monitoring technique, affecting the base of the structure, have been applied to the model, allowing to carry out a new pushover analysis in a multi-risk perspective.

In the two cases, the evolution of the stress-strain condition in the members has a different evolution. Since the landslide-induced displacements vary among all the columns bases, the phenomenon causes the born of a heterogeneous stresses path in the structural elements, that becomes the starting condition for the application of the design seismic action. For this reason, in the LAN+EQ scenario, the number of elements exceeding the LS-ls increases.

Moreover, the illustrated results remark that by neglecting the effects of the existing differential displacements landslide-induced, the safety index overestimates the threshold of the seismic safety. It is important to underline that an overestimation of $\zeta_{E}$ can conduct to an underestimation in the definition of the structural retrofit procedures and of their costs.

\section{Acknowledgements}

The authors would like to acknowledge Eng. Giuseppe Comella who has contributed to the development of presented work.

\section{REFERENCES}

[1] A. B. Liel, C.B. Haselton, G. G. Deierlein, Seismic collapse safety of reinforced concrete buildings. II: Comparative assessment of nonductile and ductile moment frames. Journal of Structural Engineering, 137(4), 492-502, 2011.

[2] M. Fragiadakis, D. Vamvatsikos, M. Aschheim, Application of nonlinear static procedures for seismic assessment of regular RC moment frame buildings. Earthquake Spectra, 30(2), 767-794, 2013.

[3] A. Miano, H. Sezen, F. Jalayer, A. Prota, Performance based comparison of different retrofit methods for reinforced concrete structures. $6^{\text {th }}$ ECCOMAS Thematic Conference on Computational Methods in Structural Dynamics and Earthquake Engineering (COMPDYN 2017), Rhodes Island, Greece, June 15-17, 2017.

[4] F. Jalayer, F., H. Ebrahimian, A. Miano, Intensity-based demand and capacity factor design: A visual format for safety checking. Earthquake Spectra, 36(4), 1952-1975, 2020.

[5] S. Arangio, F. Calò, M. Di Mauro, M. Bonano, M. Marsella, M. Manunta, An application of the SBAS-DInSAR technique for the assessment of structural damage in the city of Rome. Structure and Infrastructure Engineering, 10(11), 1469-1483, 2014. 
[6] N. Cavalagli, A. Kita, S. Falco, F. Trillo, M. Costantini, F. Ubertini, Satellite radar interferometry and in-situ measurements for static monitoring of historical monuments: The case of Gubbio, Italy. Remote Sensing of Environment, 235, 111452, 2019.

[7] A. Drougkas, E. Verstrynge, K. Van Balen, M. Shimoni, T. Croonenborghs, R. Hayen, P.Y. Declercq, Country-scale InSAR monitoring for settlement and uplift damage calculation in architectural heritage structures. Structural Health Monitoring, 1475921720942120, 2020.

[8] D. Peduto, G. Pisciotta, G. Nicodemo, L. Arena, S. Ferlisi, G. Gullà, ... , D. Reale, A procedure for the analysis of building vulnerability to slow-moving landslides. $1^{\text {st }}$ IMEKO International Workshop on Metrology for Geotechnics, Benevento, Italy, March 17-18, 2016.

[9] D. Infante, P. Confuorto, D. Di Martire, M. Ramondini, D. Calcaterra, Use of DInSAR data for multi-level vulnerability assessment of urban settings affected by slow-moving and intermittent landslides. Procedia Engineering, 158, 470-475, 2016.

[10] D. Infante, D. Di Martire, P. Confuorto, S. Tessitore, R. Tòmas R, D. Calcaterra, M. Ramondini, Assessment of building behavior in slow-moving landslide-affected areas through DInSAR data and structural analysis. Engineering Structures, 199, 109638, 2019.

[11] M. Del Soldato, L. Solari, F. Poggi, F. Raspini, R. Tomás, R. Fanti, N. Casagli, LandslideInduced Damage Probability Estimation Coupling InSAR and Field Survey Data by Fragility Curves. Remote Sensing, 11(12), 1486, 2019.

[12] A. Miano, A. Mele, D. Calcaterra, D. Di Martire, D. Infante, A. Prota, M. Ramondini, The use of satellite data to support the structural health monitoring in areas affected by slow-moving landslides: a potential application to reinforced concrete buildings. Structural Health Monitoring, 1475921720983232, 2021

[13] C. Negulescu, T. Ulrich, A. Baills, D. M. Seyedi, Fragility curves for masonry structures submitted to permanent ground displacements and earthquakes. Natural hazards, 74(3), 1461-1474 2014.

[14] M. Di Domenico, P. Ricci, G. M. Verderame, Empirical calibration of hysteretic parameters for modelling the seismic response of reinforced concrete columns with plain bars. Engineering Structures, 112120, 2021.

[15] T. B. Panagiotakos, M. N. Fardis, Seismic response of infilled RC frames structures, $11^{\text {th }}$ world conference on earthquake engineering, Acapulco, México, June 23-28, 1996.

[16] A. K. Gabriel, R. M. Goldstein, H. A. Zebker, Mapping small elevation changes over large areas: Differential interferometry. Journal of Geophysical Research, 94, 9183-9191, 1989.

[17] C. Colesanti, J. Wasowski, Investigating landslides with space-borne Synthetic Aperture Radar (SAR) interferometry. Engineering Geology, 88, 173-199, 2006.

[18] M. Costantini, A. Ferretti, F. Minati, S. Falco, F. Trillo, D. Colombo, ... ,S. Costabile, Analysis of surface deformations over the whole Italian territory by interferometric processing of ERS, Envisat and COSMO-SkyMed radar data. Remote Sensing of Environment, 202, 250-275, 2017.

[19] P. Ezquerro, M. Del Soldato, L. Solari, R. Tomás, F. Raspini, M. Ceccatelli, J. A. FenandezMerodo, N. Casagli, G. Herrera, G. Vulnerability assessment of buildings due to land subsidence using InSAR data in the ancient historical city of Pistoia (Italy). Sensors, 20(10), 2749, 2020.

[20] DM 17/01/18 (2018) Norme tecniche per le costruzioni, Ministerial Decree, 2018. (in italian)

[21] Eurocode 8, EN1998-3, Design of structures for earthquake resistance, Part 3: Assessment and retrofitting of buildings, CEN, Brussels, 2005.

[22] E. Cosenza, C. Del Vecchio, M. Di Ludovico, M. Dolce, C. Moroni, A. Prota, E. Renzi, The Italian guidelines for seismic risk classification of constructions: technical principles and validation. Bulletin of Earthquake Engineering, 16(12), 5905-5935, 2018. 
[23] R. Frascadore, M. Di Ludovico, A. Prota, G. M. Verderame, G. Manfredi, M. Dolce, E. Cosenza, Local strengthening of reinforced concrete structures as a strategy for seismic risk mitigation at regional scale. Earthquake Spectra, 31(2), 1083-1102, 2015.

[24] G. Franceschetti, M. Migliaccio, D. Riccio, G. Schirinzi, SARAS: a synthetic aperture radar (SAR) raw signal simulator. IEEE Transactions on Geoscience and Remote Sensing, 30(1) 110 123, 1992.

[25] A. Ferretti, C. Prati, F. Rocca, Permanent scatterers in SAR interferometry. IEEE Transactions on Geoscience and Remote Sensing. 39(1), 8-20, 2001.

[26] Circolare n. 7 C.S.LL.PP. 21 gennaio 2019 (2019), Commentary to NTC 2018 (in Italian).

[27] T. Vidic, P. Fajfar, M. Fischinger, Consistent inelastic design spectra: strength and displacement. Earthquake Engineering \& Structural Dynamics, 23(5), 507-521, 1994.

[28] P. Fajfar, Capacity spectrum method based on inelastic demand spectra, Earthquake Engineering \& Structural Dynamics, 28(9), 979-993, 1999.

[29] P. Fajfar, A nonlinear analysis method for performance-based seismic design, Earthquake Spectra, 16(3), 573-592, 2000.

[30] Eurocode 2, EN 1992-1-1, Design of concrete structures, Part 1-1: General rules and rules for buildings, CEN, Brussels, 2004.

[31] Eurocode 8, EN 1998-1, Design of structures for earthquake resistance, Part 1: General rules, seismic actions and rules for buildings, CEN, Brussels, 2003.

[32] Hydro-geomorphological Setting Plan of South Campania River Basin Authority, Via De Gasperi 28, 80133, Naples, Italy, 2012.

[33] F. Calò, D. Calcaterr, A. Iodice, M. Parise, M. Ramondini, Assessing the activity of a large landslide in southern Italy by ground-monitoring and SAR interferometric techniques. International Journal of Remote Sensing, 33(11), 3512-3530, 2012.

[34] D. Di Martire, M. Ramondini, D. Calcaterra, Integrated monitoring network for the hazard assessment of slowmoving landslides at Moio della Civitella (Italy). Rendiconti Online Società Geologica Italiana, 35, 109-112, 2015.

[35] D. Infante, P. Confuorto, D. Di Martire D, et al, L'utilizzo di dati DInSAR per la valutazione delle conseguenze indotte sugli edifici da frane intermittenti a cinematica lenta. XXVI Convegno Nazionale Di Geotecnica. Rome, Italy, June 20-22, 2017.

[36] R.D.L. 16 novembre 1939 n²229 (Suppl. Ord. alla Gazz. Uff. del 18 aprile 1940 n92) Norme per l'esecuzione delle opere in conglomerato cementizio semplice od armato, 1939.

[37] G. M. Verderame, A. Stella, E. Cosenza, Le proprietà meccaniche degli acciai impiegati nelle strutture in ca realizzate negli anni'60. X Convegno nazionale "L'Ingegneria Sismica in Italia", Potenza, Matera, September 9-13, 2001.

[38] G. M. Verderame, G. Manfredi, G. Frunzio, Le proprietà meccaniche dei calcestruzzi impiegati nelle strutture in cemento armato realizzate negli anni " $60 . X$ Convegno nazionale “L'Ingegneria Sismica in Italia”, Potenza, Matera, September 9-13, 2001.

[39] P. Ricci, M. Di Domenico, G. M. Verderame, Experimental assessment of the in-plane/out-ofplane interaction in unreinforced masonry infill walls. Engineering Structures, 173, 960-978, 2018.

[40] G. K. Al-Chaar, Evaluating Strength and Stiffness of Unreinforced Masonry Infill Structures. ERDC/CERL TR-02-1, 2002.

[41] M. N. Fardis, Seismic Design, Assessment and Retrofitting of Concrete Buildings: based on EN-Eurocode 8, Vol.8. Springer Science \& Business Media, 2009. 
[42] SAP2000 v21.0.2, Computers and Strucrures, Inc., 2019.

[43] P. Sacco, M. L. Battagliere, M. G. Daraio, A. Coletta, The COSMO-SkyMed constellation monitoring of the Italian territory: the Map Italy project. $66^{\text {th }}$ International Astronautical Congress (IAC 2015), Jerusalem, Istrael, October 12-16, 2015.

[44] O. Mora, J. J. Mallorquí, A. Broquetas, Linear and non-linear terrain deformation maps from a reduced set of interferometric SAR images. IEEE Transactions on Geoscience and Remote Sensing, 41, 2243-53, 2003.

[45] R. Iglesias, J. J. Mallorqui, D. Monells, C. Lopez-Martinez, X. Fabregas, A. Aguasca, J. A. Gili, J. Corominas, PSI Deformation Map Retrieval by means of Temporal Sublook Coherence on Reduced Sets of SAR Images, Remote Sensing, 7, 530-563, 2015.

[46] A. Miano, H. Sezen, F. Jalayer, A. Prota, Performance Based Assessment and Retrofit of Non ductile Existing Reinforced Concrete Structures. Structures Conference 2018, April 19-21, Fort Worth, Texas, 2018.

[47] A. Miano, F. Jalayer, R. De Risi, A. Prota, G. Manfredi G., A case-study on scenario-based probabilistic seismic loss assessment for a portfolio of bridges. $12^{\text {th }}$ international conference on applications of statistics and probability in civil engineering (ICASP), Vancouver, Canada, July $12-15,2015$.

[48] Ministerial Decree n. 24, 09/01/2020, Sisma Bonus - Linee guida per la classificazione del rischio sismico delle costruzioni nonché le modalità per l'attestazione, da parte di professionisti abilitati, dell'efficacia degli interventi effettuati, 2020. 